\title{
APPLICATION OF FMEA METHODOLOGY FOR CHECKING OF CONSTRUCTION'S PROJECT DOCUMENTATION AND DETERMINATION OF THE MOST RISK AREAS
}

\author{
Martin TuháčeK*, Ondřej Franek, Pavel Svoboda
}

\author{
Czech Technical University in Prague, Faculty of Civil Engineering, Department of Construction Technology, \\ Thákurova 7, 16000 Prague, Czech Republic \\ * corresponding author: martin.tuhacek@fsv.cvut.cz
}

\begin{abstract}
The article deals with an innovative method designed to check project documentation of buildings at the design stage, specifically exploring the possibility to implement FMEA and PDCA methodologies. Based on performed measurements and data collection, it theoretically determines the riskiest areas of the project documentation, which should be given special attention in order to reduce later costs for construction companies to fix the reported complaints. The research proves that the application of the FMEA and PDCA methodology can be very useful regarding the elimination of defects in the project documentation of constructions already in the phase of construction preparation.
\end{abstract}

KEYwORDS: Quality control, civil engineering, construction, project, project documentation, construction defects, FMEA, PDCA.

\section{INTRODUCTION}

High quality project documentation is a basic prerequisite for the final quality of a construction project. The quality of the submitted project documentation in the design phase significantly affects the result of the construction project after its completion and during usage, both in financial and qualitative terms [1]. The issue of the project documentation quality in the commercial sector is often underestimated. Experience from practice proves that the processed project documentation suffers from many shortcomings, this is also confirmed by the following results of the analysis of expert opinions, which researches the cause of defects in construction projects [2].

Figure 1 shows an analysis of 537 expert opinions that were prepared in the years 2007 - 2015. A total of 346 defects (i.e., $64 \%$ ) were related to the design or the concept itself (i.e., a defect that was already present in the project documentation of the construction).

Because of the confirmation of the connection between the design - project documentation and project defects, this research was focused on creating a tool for the determination of the risk of individual claimed defects. The assessment of the risk factor of the claimed defects subsequently helps to focus the quality control of newly submitted project documentations on critical commodities from a financial point of view.

This makes it possible to target the quality control of project documentation on commodities, the defect of which causes large financial losses to construction companies. This issue can also be based on already existing regulations that deal with the practical experience of the claimed defects in new audited projects, or it is a principle of continuous quality improvement $[3$. Beside the quality of the project documentation, it has a significant impact on the quality of the final product realization and the quality of maintenance during the operation of the building 44, 5. The issue of the building operation is directly related to the need to implement operating parameters before creating the project documentation.

Prescribed technical regulations determining the cycles for the replacement of components and equipment, together with the building user guide, can make a significant contribution to the final quality of a construction project during the project's life cycle [6]. The worldwide trend in the preparation of construction projects is shifting towards increasing the quality already in the design phase (i.e., their thorough preparation) 7. In connection with the effective preparation of construction projects, we increasingly encounter the term Lean Construction [8, 9].

The idea and effect of applying the "Lean" approach can clearly be seen in the following figure 2 with MacLeamy curve [7]. The MacLeamy curve shown in Figure 2 describes the current status during the traditional construction project. Curve with the number one clearly shows the possibility of influencing the costs and required properties of the construction project over time. The red curve with the number two then indicates how to increase the cost of any construction project incorporating changes based on a progressive realization and creation of construction documents. The vertical lines divide the individual stages of the project documentation. The graph clearly shows which levels of project documentation need attention (i.e., in particular, it is possible to influence the quality and financial intensity of the construction in the preparation phase).

Within the methods that are applied in Lean Construction [8, 9] there is an emphasis on the maximum 


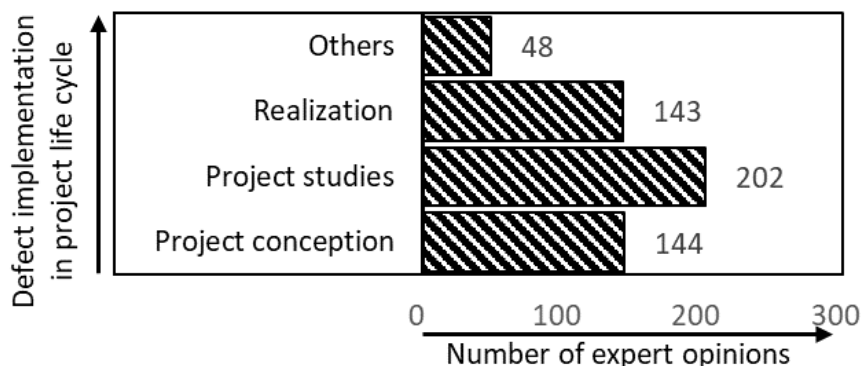

Figure 1. Causes of failures - analysis of expert opinions in the years $2007-2015$.

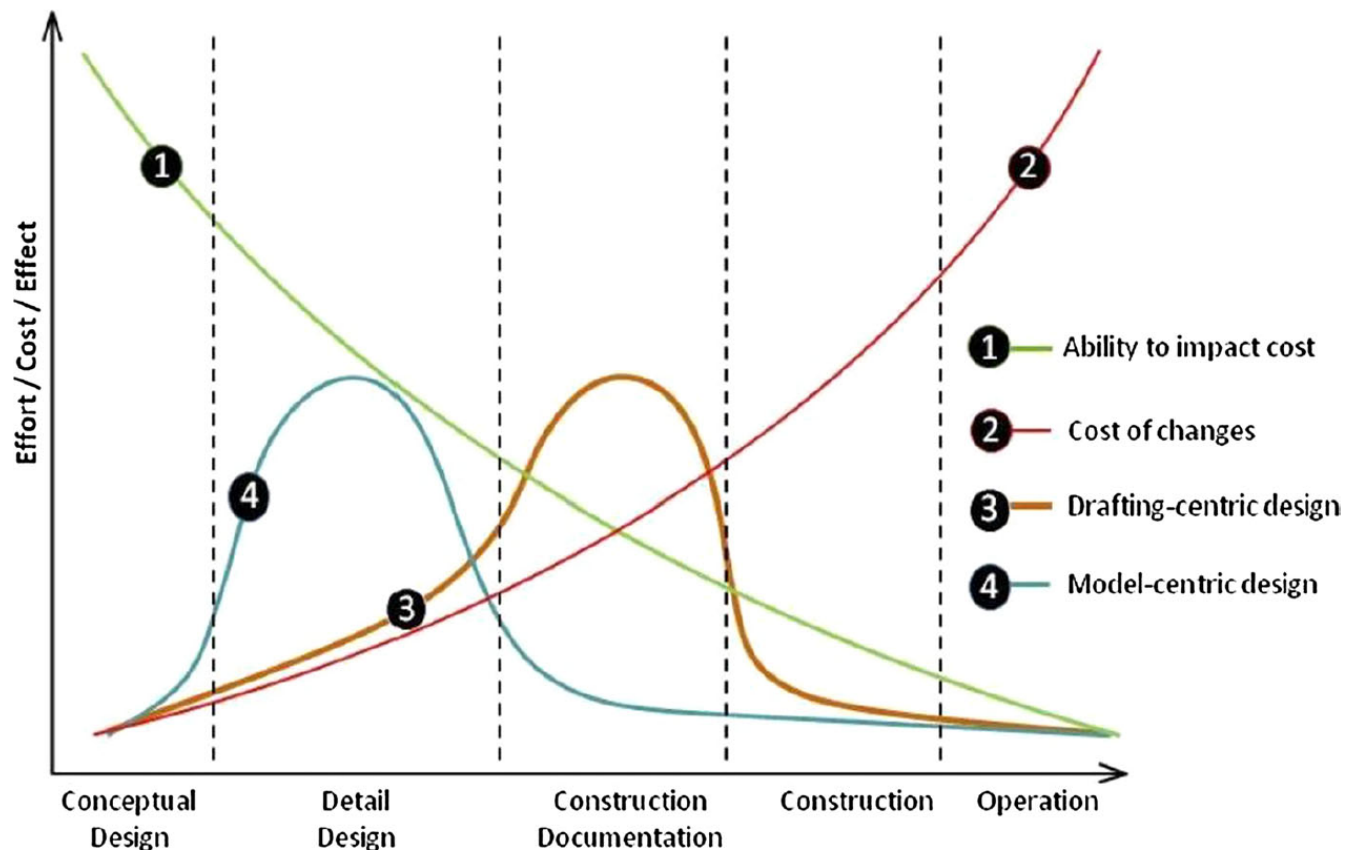

Figure 2. MacLeamy Curve - Distribution of effort in relation to project changes across project development phases 7 .

preparation of the construction project in its initial phase.

This phase is very important especially in the field of construction, where each construction project is unique in its own way and requires a proper preparation, especially in this phase. Any further interventions in the emerging project are costlier as the project progresses and there is an effort to avoid careful preparation and it is necessary to eliminate such interventions as much as possible.

Based on the above, it can be stated that it is better to check the project documentation already in the preparation phase [10, 11].

For a higher efficiency of the project documentation quality checking, the present research presents and describes computational models, thanks to which it is possible to obtain data from an analysis of claimed defects. The aim of the research is to analyse construction defects on the basis of a set of claimed defects in completed constructions. Data were collected on the basis of the claimed defects within a large construction company in the Czech Republic and has focused on building construction.
The research is based on theoretical formulas applied to practical measurements in the analysis of claimed defects.

\section{MATERIALS AND METHODS}

\subsection{EXPERT ANALYSIS AND THEIR USE FOR THE DOCUMENTATION CHECKING}

In general, the research is based on the application of theoretical knowledge based on data that were obtained by provided measurements. Based on the calculation model and the obtained data, it is possible to obtain a comprehensive overview of defects that have the most significant impact on the financial performance of the building unit with regard to the implementation of buildings. The FMEA method (Failure Mode and Effects Analysis), the PDCA cycle (Plan-Do-Check-Act) and the basic Parret rule are used as theoretical relations. The use of expert analyses in the issue of the quality control of the project documentation depends mainly on the set of processed data and required outputs. The analysis of the claimed defects is based on the FMEA method. The FMEA method is a verbal-numerical, qualitative- 
quantitative rating method used to assess the failure rate of planned projects in risk analysis, quality management and many other areas. Originally, the FMEA was developed to analyse complex processes and identify their shortcomings, especially in the engineering industry. It was developed for the government agency NASA for the purposes of space research, specifically for the Apollo program, but it has also found its application in nuclear energy sector. Subsequently, the FMEA method spread to other industries and has found extensive application in the automotive industry. The research assumes that in addition to the engineering industry, the method can also be applied in the construction industry. The FMEA method is used to determine the risks of the project documentation, and the construction project is described for this method, including the determination of individual aspects that require increased attention, with current knowledge of potential risks and impacts faced by the construction project 12 .

Depending on what is the subject of the analysis, the FMEA method is further divided into design (researches the causes of defects), process (looks for the causes of defects in the product production process), system (a combination of both previous variants) [13].

The target value of any variant of the FMEA method is the $R P N$ index (risk priority number), defined by the general formula (1) [12].

$$
R P N=R t_{1} \times R t_{2} \times \cdots \times R t_{m}
$$

Where: $R P N$ is the risk priority number [-], $R t_{1}$ to $R t_{m}$ are dimensionless expert ratings [-] of attributes 1 to $\mathrm{m}$, where $m$ is the number of the evaluation criteria chosen by the evaluator, which assigns it to individual pairs $[M, E]$, where $M$ is the cause of the defect and $E$ is the consequence of the defect.

At the same time, the overall riskiness of the project can be determined using the FMEA method. This is determined by summing the $R P N$ values found for all $M$ pairs identified using the equation (2] [12].

$$
R P N_{\text {tot }}=\sum_{K=1}^{K=M} m R P N_{K}
$$

Where: $R P N_{t o t}$ is the total risk of the project [-], $M$ is the cause of the defect [-], $m$ is the number of the evaluation criteria chosen by the evaluator [-], $R P N_{K}$ is the partial risk of the priority number for item $K$.

The total riskiness of the project is determined in order to verify the effect of the project modification on its risk compared to the original project, where the original project can be marked $R P N_{\text {tot }}(O R I)$, and the corrected project compared to the original can be marked as $R P N_{\text {tot }}(O R I+1)$.

The FMEA method has been modified and adapted in a previous research for use in the field of quality of project documentation of constructions, specifically for the categorization of product or process defects [12], where the FMEA method determines the IDP defect priority index, which is represented by relation (3) [12.

$$
I D P=S_{v} \times R_{m}
$$

Where: $I D P$ is the index of defect priority [-], $S_{v}$ is the severity of the consequences of the defect [-], $R_{m}$ is the degree of removability [-], while the values are determined by the evaluator, the scale of values is recommended to be chosen as an even number. The scale can be perceived as penalty points by which the respective defect is evaluated.

For the purposes of this research, general formula (3) is used according to the notation of formula (4).

$$
I D P=M_{v} \times R_{m}
$$

Where: $M_{v}$ is the index of the costs incurred to rectify the defect, for $I D P$ and $R_{m}$ the definition given for formula (3) applies.

The FMEA method can be suitably implemented in the risk analysis, where the subjects of evaluation are the above-mentioned pairs $[M, E]$, which take into account three basic attributes, namely the severity of the $S_{v}$, disorder, the probable possibility of $L_{k}$ disorder and the possibility of detecting the fault before its manifestation or later $D_{t}$.

The values of these criteria are determined by the evaluator. While using the FMEA method for the risk analysis, it is also necessary to pay attention to less frequent cases. Despite them being cases with low probability scenarios, they can have very serious consequences, which is why it is necessary to proceed in isolation. It can happen that the detected value $R P N=4$ (for a given four-point scale) is insignificant with respect to the value $R P N_{\max }=4^{3}=64$. However, the severity of this fault can be considerable $S_{v}=4$, while the probability of the occurrence of the $L_{k}=1$ and the detection of the fault $D_{t}=1$ is negligible. It was necessary to determine the values of the evaluation criteria for the research. From the point of view of the criterion $M_{v}$, each evaluation criterion comprises four evaluation levels, the influence of the defect on the repair price being monitored at each level. The risk is, therefore, derived according to the financial impact on the elimination of the defect $c$. The values of the criterion $M_{v}$ are shown in Table 1

In terms of the criteria $R_{m}$ that expresses the intensity of removability defects, the values are sorted from easily correctable defects to defects whose removal is quite complicated. As an example, elaborately removable defects include dysfunctional system of waterproofing substructures. The values of the $R_{m}$ criterion are shown in Tab. 2

From the above tables, it is clear that expert ratings take values from 1 to 4 . The individual values chosen to perform the researched measurement can be understood as penalty points. If the value is higher, this makes the defect morerisky. Individual defects are divided into categories in the research using metadata, 


\begin{tabular}{cc}
\hline The cost $c$ of removing the defect $[\mathrm{EUR}]$ & $M v$ \\
\hline$c<750$ & 1 \\
$750 \leq c<1500$ & 2 \\
$1500 \leq c<2250$ & 3 \\
$c>2250$ & 4 \\
\hline
\end{tabular}

TABle 1. Determination of defect price groups for criterion $M_{v}$.

\begin{tabular}{cc}
\hline Difficulty in removing the defect & $R_{m}$ \\
\hline Practically impossible & 4 \\
Difficult to remove (time and fin. side) & 3 \\
Easy (but time realization) & 2 \\
Unpretentious (time and realization) & 1 \\
\hline
\end{tabular}

TABle 2. Determination of groups according to the difficulty of removing the defect $R_{m}$.

and it is therefore possible to evaluate the data set and identify the weakest group of claimed defects and focus on it as a part of the project documentation and subsequent implementation in the production.

For this purpose, the research introduces the socalled defect priority index $I D P_{K}$, which is based on relation (2). $I D P_{t o t}$ is the average value of the defect priority indices of individual defects in a given category. For the purposes of our research, it is determined by relation (5). For this purpose, the research introduces the so-called defect priority index $I D P_{K}$, which is based on relation (2). IDP tot is the average value of the defect priority indices of individual defects in a given category. For the purposes of our research, it is determined by relation (5).

$$
I D P_{\text {tot }}=\sum_{K=1}^{K=M} \frac{I D P_{K}}{N}
$$

Where: $I D P_{t o t}$ is the average value of the defect priority indices [-], IDP $P_{K}$ is the defect priority index of the partial defect, $N$ is the number of defect priority indices. Based on the comparison of individual categories, it is possible to identify the group with the highest risk and focus the attention during the quality check primarily on it. Also, the risk assessment can be provided according to ISO 31000:2018 Risk management - Guidelines.

\subsection{A SYSTEM OF CONTINUOUS QUALity IMPROVEMENT}

Continuous quality improvement is the basis of any quality management system and consists of planning, manufacturing, checking(inspecting) and improving the monitored product. An illustrative example of how a continuous quality improvement system works is the PDCA cycle.

The PDCA cycle is an interactive repetitive cyclic method that is based on four steps - plan, do, check, act. The basic principle of this scientific method is its repetition. After completing the entire cycle, in its last phase, the knowledge is evaluated and applied to production. Subsequently, the whole process is repeated to verify the application of the improvement and, if necessary, to identify new weaknesses in the process that need to be improved again.

This fulfils the idea of a continuous quality improvement and striving for a perfect operation. Repeated implementation of the PDCA cycle is often also described by a spiral, which is supposed to symbolize increasing knowledge about the system towards the set goal. Each new cycle should be closer to its goal. Each subsequent application of the cycle then brings higher knowledge about the system as a whole, which is researched and improved using this method.

\subsection{Pareto RUle}

Based on this rule, it can be stated that $20 \%$ of causes are responsible for $80 \%$ of complications. It is important to apply such a fact in terms of work efficiency in solving quality problems. In practice, the Pareto diagram began to be more prominent only thanks to J. M. Juran, who used previous knowledge to compile the Pareto diagram. At the same time, based on his experience, he argued that $5 \%$ to $20 \%$ of causes are responsible for $80 \%$ to $95 \%$ of problems regarding quality and its management. This makes this method the most commonly used in the field of quality management and at the same time, very suitable for identifying priorities [13].

\section{Results}

\subsection{DATA COLlECtion AND MEASUREMENT}

For the purposes of the research, measurements, or a comprehensive collection of data on the claimed defects was performed within the operating unit of a large construction company operating in the Czech Republic. The data were collected from 2017 to 2018, in the form of in-house records for the management of claimed defects. The volume of the building unit's orders in the field of building construction exceeded EUR 75.5 million in those years. The number of 


\begin{tabular}{ccc}
\hline Year of monitoring & $\begin{array}{c}\text { Value of deffects } \\
\text { [EUR] }\end{array}$ & $\begin{array}{c}\text { Number of deffects } \\
\text { [pieces] }\end{array}$ \\
\hline 2017 & 295836 & 2327 \\
2018 & 453821 & 2734 \\
\hline
\end{tabular}

TABLE 3. The number and financial volume of claimed defects of the researched construction company in 2017 and 2018.

claimed defects and their financial volume for repairs in individual years is shown in Table 3

From Table 3, it is evident that in 2017, a total of 2327 defects in the total financial volume of EUR 295.836 were claimed in the measured company. In 2018, 2.734 defects were claimed in a total financial volume of EUR 453.821. In 2017 and 2018, a total of 5061 defects were claimed in a total financial volume of EUR 711.475. Table 4 provides an overview of claimed defects for the years 2017 and 2018, specifically their financial volume and number divided into subcategories, according to professional areas. Table 4 is divided into the following 21 professional categories: $\mathrm{A}$ - insulation against water and moisture of the superstructure, B - external surface treatment (ETICS), C - hole fillings, D - high current, E - insulation against water and moisture substructure, F - floors and floor coverings, $\mathrm{G}$ - internal surface treatment, $\mathrm{H}$ - other unclassified defects, I - air conditioning and cooling, $\mathrm{J}$ - tiling and paving, $\mathrm{K}$ - low current, L - internal water supply and sewerage, $\mathrm{M}$ - fixtures, $\mathrm{N}$ - central heating, O - surface treatment of metal structures and corrosion, P - internal dividing and visible structures, $\mathrm{Q}$ - monolithic reinforced concrete structures, $\mathrm{R}$ - masonry structures, $\mathrm{S}$ - measurement and regulation, $\mathrm{T}$ light perimeter cladding incl. shielding systems, U other surface treatments.

\subsection{Applications of COMputational MODELS}

Within the research, a computational models (4) and (5) were applied to the obtained data to determine the riskiness of the claimed defects. Due to the extent of the data obtained, it was appropriate to use the sorting of claimed defects according to the calculated risk. The obtained data divided into subcategories and sorted according to the $R P N$ indicator are shown in Table 5

Table 5 shows that the riskiest construction technologies include A, which shows a total of 232 reported defects in 2 years with a financial volume of EUR 224.208 and an $R P N$ of 5.75 [-]. The financial volume for repairs, of this item only, is several times higher than for any other solution. The second place, according to the $R P N$ indicator, is the area of $\mathrm{B}$ with an average $R P N$ of 5.65 [-], then the area of $\mathrm{E}$ with an $R P N$ of 5.33 [-], $\mathrm{C}$ with an $R P N$ of 5.10 [-], the remaining professions have an $R P N$ of less than 5.00 [-]. By applying Pareto's rule (i.e., selecting approximately $20 \%$ of the most risky items),

\begin{tabular}{ccr}
\hline $\begin{array}{c}\text { Building } \\
\text { technology }\end{array}$ & $\begin{array}{c}\text { Number } \\
\text { of defects } \\
\text { [pieces] }\end{array}$ & $\begin{array}{r}\text { Costs } \\
\text { [EUR] }\end{array}$ \\
\hline A & 232 & 224208 \\
B & 34 & 76000 \\
C & 888 & 58445 \\
D & 324 & 50834 \\
E & 392 & 49253 \\
F & 319 & 47211 \\
G & 534 & 34585 \\
H & 232 & 29985 \\
I & 314 & 28547 \\
J & 597 & 23642 \\
K & 318 & 19189 \\
L & 191 & 18004 \\
M & 189 & 12721 \\
N & 176 & 9381 \\
O & 41 & 6755 \\
P & 62 & 6547 \\
Q & 58 & 5755 \\
R & 102 & 4415 \\
S & 23 & 3038 \\
T & 18 & 2151 \\
U & 17 & 811 \\
\hline
\end{tabular}

TABLE 4. The number and financial volume of claimed defects of the researched construction company in 2017 and 2018 .

the risk coverage of $80 \%$ of future complaint costs should theoretically be achieved. However, by summing up the values of the claimed areas of $\mathrm{A}, \mathrm{B}, \mathrm{E}$ and $\mathrm{C}$ (a total of $19.0 \%$ of items) we get the value of EUR 407.906, which is only $57.3 \%$ of the total amount of EUR 711.475. The results of the RPN according to individual professional areas are clearly shown in Figure 3 .

Figure 3 shows that in the case of the application of the $R P N$ indicator, which, in addition to the price, also takes into account the possibility of remediation of the defect, cheaper occupations may also prove to be riskier than areas with higher costs for removal.

\section{Discussion}

Measurements and calculations showed that in terms of the dividing of defects, the Pareto rules cannot be reliably used for the construction industry, with calculations performed by this research showing that approximately $19 \%$ of the most significant items, ac- 


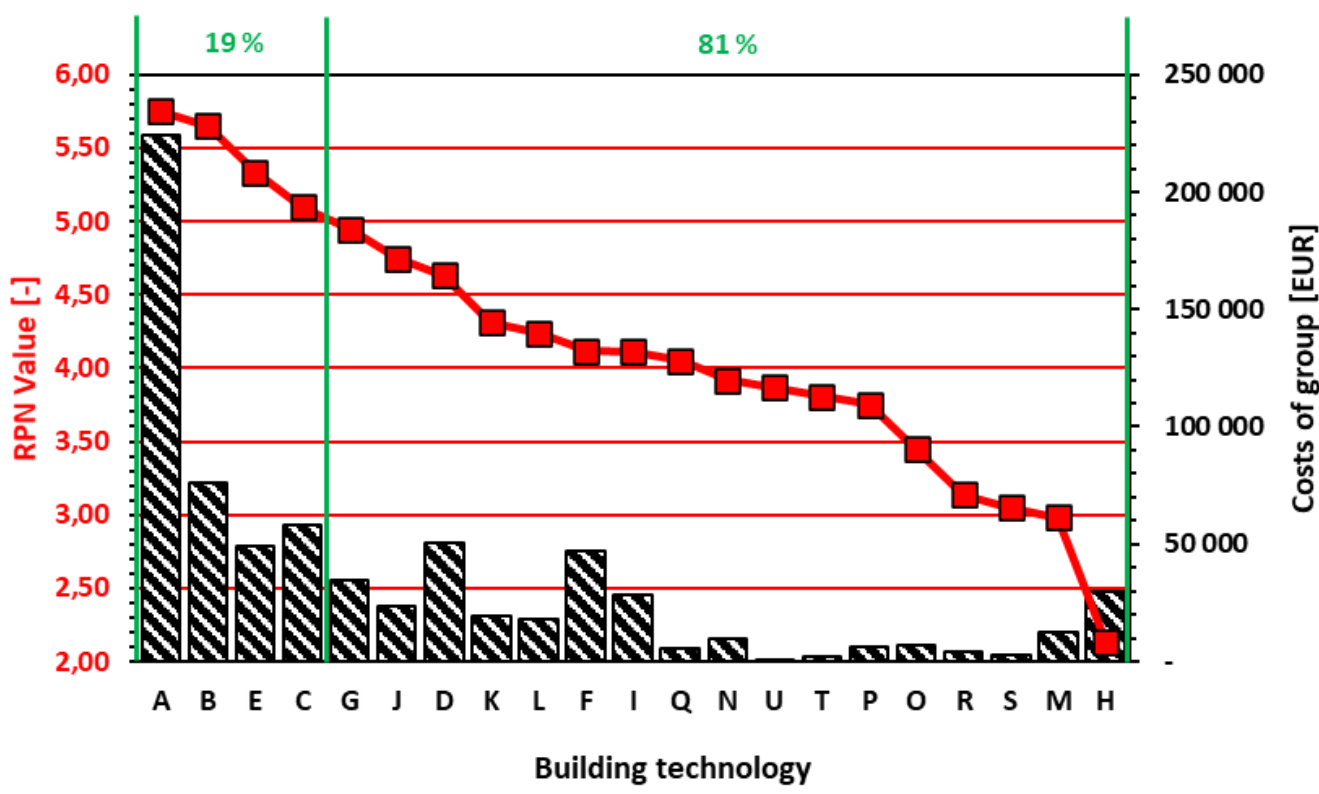

WCosts [EUR] $\quad \square$ RPN [-]

FigURE 3. Sorting of individual professional areas according to the average value of the $R P N$ of claimed defects based on the measured data and application of computational models.

\begin{tabular}{ccrc}
\hline $\begin{array}{l}\text { Building } \\
\text { technology }\end{array}$ & $\begin{array}{c}\text { Number } \\
\text { of defects } \\
\text { [pieces] }\end{array}$ & $\begin{array}{r}\text { Costs } \\
\text { [EUR] }\end{array}$ & $\begin{array}{c}R P N \\
{[-]}\end{array}$ \\
\hline $\mathrm{A}$ & 232 & 224208 & 5.75 \\
$\mathrm{~B}$ & 34 & 76000 & 5.65 \\
$\mathrm{E}$ & 392 & 49253 & 5.33 \\
$\mathrm{C}$ & 888 & 58445 & 5.10 \\
$\mathrm{G}$ & 534 & 34585 & 4.95 \\
$\mathrm{~J}$ & 597 & 23642 & 4.75 \\
$\mathrm{D}$ & 324 & 50834 & 4.63 \\
$\mathrm{~K}$ & 318 & 19189 & 4.31 \\
$\mathrm{~L}$ & 191 & 18004 & 4.24 \\
$\mathrm{~F}$ & 319 & 47211 & 4.12 \\
$\mathrm{I}$ & 314 & 28547 & 4.11 \\
$\mathrm{Q}$ & 58 & 5755 & 4.05 \\
$\mathrm{~N}$ & 176 & 9381 & 3.92 \\
$\mathrm{U}$ & 17 & 811 & 3.87 \\
$\mathrm{~T}$ & 18 & 2151 & 3.81 \\
$\mathrm{P}$ & 62 & 6547 & 3.75 \\
$\mathrm{O}$ & 41 & 6755 & 3.45 \\
$\mathrm{R}$ & 102 & 4415 & 3.14 \\
$\mathrm{~S}$ & 23 & 3038 & 3.05 \\
$\mathrm{M}$ & 189 & 12721 & 2.98 \\
$\mathrm{H}$ & 232 & 29985 & 2.13 \\
\hline
\end{tabular}

TABLE 5. The number and financial volume of claimed defects of the researched construction company according to professional areas for the years 2017 and 2018 sorted according to the calculated $R P N$. cording to the $R P N$ indicator, affect only $57.3 \%$ of total costs. The performed research also shows that, thanks to the $R P N$ indicator, it is possible to evaluate not only the financial risks in the field of eliminating claimed defects but also the complexity of removing individual defects. Comparing Table 3 and Table 4 it is clear that when the $R P N$ indicators are not used, priorities are given to the control of professional areas A, B, C, D, which make up to $19 \%$ of majority professional areas in terms of financial impact, but the cost of remedying the defects is not taken into account. The use of the $R P N$ indicators allows to include these costs as well. It can, therefore, be stated that the $R P N$ indicator is capable of a multi-criteria optimization in terms of determining the majority of professional areas for checking (inspecting) the project documentation already in the preparation phase.

In the performed measurement, the researched data within the construction company were limited by the warranty period. After its expiration, the construction contractor loses control over the further operation of the building. This can be solved by an ongoing data collection by the facility management, which then takes over the management of the building. The data collection from the facility management can provide other valuable data that can be further analysed. The output of such an analysis can provide valuable data for the design and preparation of design work for construction projects, which will increase the resulting quality of buildings. The aim of the analyses is to obtain current reports on the claimed defects at any time.

At the same time, the question of the need for interconnection and transmission of information within 
the entire life cycle of the construction is raised. The building must be designed for the intended purpose, built in an accordance with the design and operated in an accordance with the proposed parameters.

A building user guide should be a part of every quality documentation. It should clearly define and coordinate the parameters for reliable operation. At the same time, the considered cycles of replacement and renewal of partial parts of the building should be stated.

\section{Conclusion}

The risk assessment of claimed defects, which the authors of the article use on the basis of the FMEA method and the PDCA cycle in the management and evaluation of claimed defects, is an effective tool for checking the project documentation of prepared construction projects.

Due to the fact that the process of registration and evaluation of claimed defects is a continuous process, the principle of a continuous quality improvement is applied by this activity.

Based on the updated results of analyses, tools for checking project documentation are presented and specified. It is appropriate that all data on the claimed defects be thoroughly analysed and subjected to computational models for a continuous updating of results, resp. specification of the majority risk areas of the project documentation.

\section{ACKNOWLEDGEMENTS}

The authors are grateful to the Czech Technical University in Prague. The presented research was supported by the grant SGS20/005/OHK1/1T/11, Czech Technical University in Prague.

\section{REFERENCES}

[1] M. Tuhacek, P. Svoboda. Quality of project documentation. IOP Conference Series: Materials Science and Engineering 471:052012, 2019. DOI:10.1088/1757-899x/471/5/052012

[2] J. Synek. Nekvalita jako funkce ztráty informací. https: //www.tzb-info.cz/bim-informacni-model-budovy/ 15018-nekvalita-jako-funkce-ztraty-informaci, 2016.

[3] ISO 9001:2015 - Quality management systems Requirements. Standard, International Organization for Standardization, Brussel, 2015.
[4] L. Vesela, J. Synek. Quality control in building and construction. IOP Conference Series: Materials Science and Engineering 471:022013, 2019. DOI:10.1088/1757-899x/471/2/022013

[5] N. Forcada, M. Macarulla, M. Gangolells, M. Casals. Handover defects: comparison of construction and post-handover housing defects. Building Research $\&$ Information 44(3):279 - 288, 2016. DOI:10.1080/09613218.2015.1039284.

[6] A. Sharma, A. Saxena, M. Sethi, et al. Life cycle assessment of buildings: A review. Renewable and Sustainable Energy Reviews 15(1):871 - 875, 2011. DOI:10.1016/j.rser.2010.09.008.

[7] J. Zhang, C. Wu, Y. Wang, et al. The BIM-enabled geotechnical information management of a construction project. Computing 100:47 - 63, 2017. DOI:10.1007/s00607-017-0571-8.

[8] A. H. A. Jamil, M. S. Fathi. The integration of lean construction and sustainable construction: A stakeholder perspective in analyzing sustainable lean construction strategies in malaysia. Procedia Computer Science 100:634 - 643, 2016. DOI:10.1016/j.procs.2016.09.205.

[9] D. Carvajal-Arango, S. Bahamón-Jaramillo, P. Aristizábal-Monsalve, et al. Relationships between lean and sustainable construction: Positive impacts of lean practices over sustainability during construction phase. Journal of Cleaner Production 234:1322 - 1337, 2019. DOI:10.1016/j.jclepro.2019.05.216

[10] Y. A. Olawale, M. Sun. Cost and time control of construction projects: inhibiting factors and mitigating measures in practice. Construction Management and Economics 28(5):509 - 526, 2010. DOI:10.1080/01446191003674519

[11] Y. Olawale, M. Sun. Construction project control in the UK: Current practice, existing problems and recommendations for future improvement. International Journal of Project Management 33(3):623 - 637, 2015. DOI:10.1016/j.ijproman.2014.10.003.

[12] M. Tichý. Ovládání rizika: analýza a management. C. H. Beck, Praha, 2006. Beckova edice ekonomie.

[13] J. Veber, M. Hůlová, A. Plášková. Management kvality, environmentu a bezpečnosti práce: legislativa, systémy, metody, praxe. Management Press, Praha, 2006. 